\title{
Estado de la archivística en América Latina 2000-2009. Perspectivas teóricas y aproximaciones conceptuales *
}

\author{
Sebastián Alejandro Marín Agudelo **
}

Artículo recibido:

14 de noviembre de 2011.

Artículo aceptado:

30 de mayo de 2012.

\section{RESUMEN}

La archivística en América Latina en los últimos años ha estado caracterizada por importantes transformaciones y permanencias, que tienen que ver esencialmente con su evolución científica y profesional. Cambios que se deben a la consigna de los archivos como lugares de concentración y reconstrucción de la memoria, las garantías ciudadanas, el control de la esfera pública, las tendencias administrativas de calidad total y la gestión de la información. Al mismo tiempo, el uso de las tecnologías de la información y la comunicación en las tareas diarias de los archivos. Se presentan las

* $\quad$ Artículo derivado de la investigación Estado del arte en archivística y archivos: América Latina 2000-2009. Desarrollado con el apoyo y financiación del Centro de Investigaciones en Ciencia de la Información. Escuela Interamericana de Bibliotecología. Universidad de Antioquia. Medellín, Colombia.

** Escuela Interamericana de Bibliotecología. Universidad de Antioquia, Medellín, Colombia. alejo.m.a18@gmail.com

INVESTIGACIÓN BiBLIOTECOLÓGICA, Vol. 26, Núm. 57, mayo/agosto, 2012, México, ISSN: 0187-358X. pp. 77-101 
principales perspectivas y tendencias teóricas, reflejadas en la producción científica sobre estos aspectos en la última década, como una manera contribuir a la construcción de un marco teórico y a la definición de líneas de investigación en el área. Utilizando la metodología de investigación documental del estado del arte.

Palabras Clave: archivística; archivos; perspectivas teóricas; América Latina.

\section{ABSTRACT}

State of the art of Archival Science in Latin America 2000-2009. Theoretical perspectives and conceptual approaches

Sebastián Alejandro Marín Agudelo

In late years, Archival Science in Latin America has been characterized by major changes related basically with its scientific and professional evolution. Changes due to the paradigm of archives as places for document concentration and memory reconstruction, citizen warranties, governmental accountability, total quality administrative trends and information management. All of these using Information Communication Technologies in archives on a current basis. This paper presents the main perspectives and theoretical trends reflected in the last decade in scientific publications about these issues as a way to contribute to build a theoretical framework and to define research lines in the field. The methodology of documentary research of state of the art is used.

Keywords: Archival Science; Archives; theoretical perspectives and trends; Latin America.

\section{INTRODUCCIÓN}

$\mathrm{D}$ urante los últimos años, en los diferentes países de América Latina los archivos han ido ganando espacios en nuevos y diversos sectores económicos y productivos de la sociedad. Estos se piensan como lugares de concentración de la memoria y de enorme riqueza para la actividad investigativa en 
distintas áreas del conocimiento, como instrumentos de control de las administraciones públicas y privadas que además garantizan el derecho a la información y la preservación de la memoria de los pueblos. De igual manera se establecen como unidades de gestión de la información en medios electrónicos y digitales.

Como resultado bilateral de tales transformaciones, los postulados en el área de la archivística como campo de conocimiento han sufrido también un cambio de paradigma, lo cual ha concluido en el análisis y evaluación de conceptos fundamentales en la práctica actual de la disciplina. En esta misma línea, la archivística ha logrado consolidarse como una disciplina de vital importancia para la salvaguarda del patrimonio documental. Emergiendo como una ciencia dinámica preocupada por el rescate de la memoria histórica y por la evolución de las tendencias administrativas.

La archivística ha diversificado sus contenidos en cuestiones como la eadministración pública, la auditoria de la información, el valor probatorio de los documentos en soportes electrónicos y digitales, etc. Ello sumado a las concepciones de los archivos en sus contextos locales o regionales, representa la realidad de estos en América Latina. Lo que de igual modo se verá reflejado en la producción científica de la comunidad académica y profesional que debate y reflexiona sobre temas puntuales de la disciplina archivística así como de aspectos concernientes a los archivos y sus relaciones con la sociedad.

\section{Metodología}

En tanto se trata de una investigación que usa como enfoque metodológico la perspectiva del "estado del arte", los objetivos de ésta son:

- Recopilar, seleccionar y sistematizar las fuentes de información más relevantes y pertinentes sobre las temáticas de investigación.

- Identificar las perspectivas teóricas de análisis e interpretación desarrolladas en América Latina en la última década, en relación con los temas de interés.

- Analizar y categorizar la información obtenida, dando cuenta de las temáticas abordadas y más desarrolladas, reflejadas en las fuentes bibliográficas.

\subsection{Enfoque metodológico}

Esta investigación es de tipo cualitativo, que utilizó como herramienta metodológica la técnica de investigación documental del estado del arte, cuyo objeto de 
estudio es la investigación previa o los conocimientos acumulados en un área del saber, disciplina o fenómeno determinado; supone la recolección y revisión cuidadosa de estudios, informes de investigación, periódicos, artículos, trabajos inéditos, es decir, la literatura existente sobre un tema específico. ${ }^{1}$

La aplicación del estado del arte permite recolectar, ordenar y analizar de manera sistemática la producción científica, teórica o práctica existente en torno a un tema de investigación, para un período de tiempo y espacio determinado (Hurtado, 2004). En este caso la archivística y los archivos en América Latina en el periodo 2000-2009. Asimismo, requiere de un trabajo de interpretación, que implica confrontar mediante preguntas orientadoras la bibliografía hallada con expertos en el campo de estudio, es decir, el ámbito archivístico.

El estado del arte da paso a otras interpretaciones en el área del conocimiento estudiado proponiendo de esta manera el rumbo que deberá tomar la investigación (Hurtado, 2004). Esta revisión permite identificar temáticas y abordajes dominantes y emergentes, así como vacíos o campos inexplorados que están abiertos a investigaciones futuras. ${ }^{2}$ Por ello, ha de precisarse que la construcción del estado del arte siempre estará supeditada a aquellas cosas que interese relevar, a aquellas preguntas que se han formulado y estará condicionada por el espacio social, cultural e institucional en el que se produce.

\subsection{Etapas metodológicas}

Ya que se trata de un trabajo que requirió de un proceso sistemático de recolección y clasificación de las fuentes para su posterior análisis e interpretación, fue necesario desarrollar las siguientes etapas:

Etapa 1. Marco conceptual: En esta etapa se construyó un estado de la cuestión o marco conceptual, para el que se tomaron en cuenta trabajos representativos para el área de la archivística y los archivos, realizados por importantes autores. Éste sirvió como base para la conceptualización temática y fundamentación del proyecto así como un primer balance de las fuentes a analizar. ${ }^{3}$

Etapa 2. Diseño de instrumentos y recolección de fuentes: En la segunda etapa se diseñaron y aplicaron los instrumentos pertinentes para la recolección y análisis de los trabajos. Estos fueron las fichas bibliográficas y analíticas (ver anexo 1). Luego de la exploración sobre la

1 Este abordaje de estado del arte puede ampliarse en: Vélez y Galeano, 2000.

2 Véase: Hadad, 2000.

Sobre la conceptualización temática y fundamentación del estado del arte, véase: Marín, 2010. 
información disponible se estableció como criterio de selección de los textos, la recolección de artículos de investigación. ${ }^{4}$ Para ello se definieron diferentes estrategias de búsqueda, categorías de análisis y preguntas orientadoras (ver anexos 3 y 4). Los artículos se recogieron en dos momentos, uno en bases de datos y otro directamente por revistas (ver anexo 5), hasta completar un total de 158 artículos, pertenecientes a diferentes temáticas, previamente establecidas por el Grupo de Investigación en Información, Conocimiento y Sociedad (Moncada y Montoya, 2009). Éstas son:

- Conocimiento de la archivística: Esta temática aborda las diferentes concepciones de los archivos en la historia; desde la Antigüedad hasta los cambiantes sistemas de información de la actualidad y el desarrollo de las tecnologías que han derivado en unos principios teóricos, en procesos estructurados para el tratamiento de los archivos y en unas tendencias de formación que se hacen evidentes por su especificidad o por el contrario por su mezcla con otras disciplinas como la bibliotecología y/o la documentación.

- Archivos, memoria y democracia: En esta temática se pretende estudiar el papel activo de los archivos en la recuperación de la memoria (histórica, social y/o colectiva), como una forma de contribuir al análisis y aplicación de la normatividad en materia de transparencia y acceso a la información y, en particular, a la promoción del uso de la información contenida en los documentos de archivo como fuente indispensable para el cambio ciudadano, cuyo vínculo entre la teoría y, la práctica archivística y la sociedad es ineludible.

- Archivos e investigación: Se pretende abordar el documento de archivo, independiente de su soporte y formato, como fuente potencial de información, producto de la actividad humana,

$4 \mathrm{Al}$ iniciar la investigación se estableció como criterio de selección de los textos la recolección de tres tipos de documentos: artículos, libros e informes de investigación. Para ello se elaboró un tipo de encuesta que serviría de instrumento para rastrear los productos de investigación formal realizada por centros de formación y/o grupos de investigación, pertenecientes a universidades o independientes (ver anexo 2). La encuesta fue enviada sin mayor respuesta a 39 escuelas de archivología y/o bibliotecología y a 8 grupos de investigación de América Latina, 11 de los correos fueron fallidos, sobre todo para el caso de Brasil. La falta de actualización de las páginas y correos, las dificultades de acceso, la poca colaboración internacional y asuntos de presupuesto, llevó a tomar la decisión de limitar la muestra a un solo tipo de documento: los artículos, ya que partimos de la idea de que estos guardan una relación directa con la investigación y el rastreo de estos planteaba mayores facilidades de acceso y análisis. 
que revela o transmite un conocimiento total o parcial para una determinada situación en el tiempo, relevante y confiable para la generación de nuevo conocimiento en cualquier rama del saber.

- Archivos y administración: Aquí se propone trabajar los archivos como células primarias de la función administrativa esenciales para la toma de las decisiones y como unidades de información y comunicación que contribuyen al cumplimiento de los objetivos de las organizaciones. Teniendo como base los nuevos conceptos de la administración moderna como el control interno, la calidad total, la gestión del conocimiento y del medio ambiente y la seguridad de la información.

- Archivos y tecnologías: En esta temática se quiere empezar a trabajar sobre el desarrollo de las tecnologías de la información y la comunicación (TIC) y su aplicación en el quehacer archivístico, cuyas implicaciones constituyen un motivo de reflexión para la archivística moderna. Especialmente en lo que tiene que ver con la seguridad de la información en las transacciones, el derecho a la intimidad y la propiedad intelectual.

Etapa 3. Sistematización y análisis: Aquí se construyeron diferentes tablas por número de artículos, países más productivos, años de mayor producción, temáticas más abordadas y revistas científicas de preferencia para la publicación de los artículos. ${ }^{5}$ Luego de la cuantificación de los resultados, se aplicaron las fichas de análisis en profundidad a 38 artículos seleccionados proporcionales al número de publicaciones correspondientes en cada una de las temáticas, con las cuales se intentó dar sentido y estructura cohesiva a las hipótesis y planteamientos de los textos. De esta etapa se reconocieron los principales enfoques teóricos evidenciados en las investigaciones, que es el tema que se tratará en este artículo.

5 Por cuestiones de espacio y practicidad, dicho abordaje cuantitativo no se incluye en este texto. Por lo que se recomienda consultar: Marín, 2011. 


\section{Resultados ${ }^{6}$}

\subsection{Construcción cientifica, profesional e histórica de la archivistica y de los archivos}

Los estudios teóricos en el área de la archivística y los archivos se encuentran inscritos entre los marcos de los clásicos disciplinares, cuyas características significaron una ruptura teórica de carácter fundacional, como es el caso del manual holandés, y el nuevo paradigma archivístico, como es enunciado por diferentes autores (Cook, Thomassen, Gilliland-Swetland, Ribeiro, Bearman, Duranti). Se apoyan en conceptos relacionados con el paradigma científico para referirse a los nuevos y tradicionales problemas de la archivística con respecto a su cientificidad, la diversidad de los usuarios, la incorporación e incidencia de las nuevas tecnologías y los nuevos servicios y productos archivísticos.

La evolución científica de la archivística es separada en etapas que coinciden en una primera que tiene que ver con un génesis disciplinar, la cual Dorado y Mena (2009:3) puntualizan al decir que:

Dicho período presenta 3 hitos importantes, que coinciden con la publicación de importantes obras de la literatura archivística. Ellos son: la edición del Manual para la organización y descripción de archivos (Manual holandés), de los holandeses Samuel Muller, Johan Feith y Robert Fruin, en 1898; del Manual de administración de archivos de Hilary Jenkinson, en 1922 y de Archivos modernos. Principios y técnicas, publicado por Theodore Schellenberg en 1956.

Estos primeros estudios enfatizan en la naturaleza de los archivos, el tratamiento de los mismos basado en los principios de procedencia y orden original, los documentos de archivos como fuentes para la investigación histórica, la valoración sustentada en la evaluación del contenido de los documentos y la independencia de la archivística.

Una segunda etapa se asocia con un cambio de paradigma de la archivística que se caracteriza fuertemente por la evolución de los fundamentos teóricos preocupados ya no por la organización de los documentos sino por su autenticidad, integridad y veracidad en medios electrónicos y virtuales. Por ejemplo se tienen en cuenta las aplicaciones tecnológicas a las tareas diarias de los archivos como criterio de conservación (Rodríguez, Montes de Oca, Dorta, 2002; Álvarez y Rodríguez, 2005).

6 Los autores referenciados en cada uno de los apartes siguientes son aquellos que fueron identificados según las citaciones en los textos analizados, sin embargo, ello no significa que sean estos las únicas autoridades en los temas para los que se toman como referencia. 
Existe un consenso generalizado entre la comunidad académica archivística con respecto a la demarcación de una segunda etapa a partir de las décadas de los 70 (otros hablan de los 80) del siglo XX, que "marcó el inicio de un proceso de profundos cambios en los postulados de esta área de conocimiento, que pueden tomarse como un cambio de paradigma" (Dorado y Mena 2009:13). En el que desde entonces se han dado importantes avances en materia de normalización como es el caso de la descripción archivística, regulada casi en su totalidad no sólo en América Latina sino a nivel internacional.

La delimitación de la archivística en momentos o periodos ha permitido el reconocimiento de importantes aportes que han ayudado a la construcción de un cuerpo teórico y de una metodología propia. Algunos de los más distintivos teóricos,

cuyo pensamiento ha dado sustento a la teoría archivística, son: Eugenio Casanova (Italia), Wolfgang Leesch (Alemania), Theodore Schellenberg (Estados Unidos), Aurelio Tanodi (Argentina), Carol Couture (Canadá), Antonia Heredia (España), entre otros (Giraldo, 2009: 35).

De cualquier forma, sobre el número de etapas en que se divida la evolución científica de la archivística, la mayoría de los autores coinciden en que el desarrollo de las nuevas tecnologías de la información y la comunicación ha significado cambios profundos en el modo en cómo se hacían las cosas en los archivos. En esta etapa se expresan nuevos contextos y funciones que los archivistas deben afrontar para el tratamiento de los documentos y los fondos documentales, para lo que se expone como imperativa una formación integrada e interdisciplinar de la archivística.

Se hacen reflexiones teóricas sobre la necesidad de incorporar a los planes de estudio, además del componente tecnológico e informático, la investigación científica, sobre todo en el contexto latinoamericano, como una exigencia de los nuevos contextos de la información, así como para la renovación teórica y la construcción de nuevo conocimiento archivístico que no sólo cubra las aptitudes y habilidades de la formación académica tradicional, sino además competencias transversales, dadas hasta ahora de la formación continua. Al respecto Jaén García (2008: 52) detalla que:

[...] en América Latina no existe una tradición investigadora en Archivística de manera formal, a partir de la academia por medio de centros y grupos de investigación, es imprescindible que las carreras de Archivística incentiven, motiven y formen a los archivistas en la investigación científica. Esta incursión en la pesquisa debe iniciarse en los estudios de bachillerato o primer nivel profesional de la formación reglada, 
a partir de la inclusión en los planes de estudios de cursos relacionados con la metodología de la investigación, que deben estar constituidos por las técnicas, los métodos, las teorías y las fuentes de información que le permitirán a los educandos adquirir los conocimientos para realizar investigaciones a partir de un tema y problema determinado.

De igual forma, la evolución histórica de los archivos ha tenido como base los estudios de R. H. Bautier (1968) y L. Sandri (1968). La historia de la archivística y de los archivos ha sido un terreno poco ahondado desde la archivística latinoamericana, sin embargo, se han comenzado a desarrollar estudios que tienen en cuenta el diálogo entre la archivística, la historia y las ciencias sociales en general; al vincularla con la cultura escrita, el arte, el derecho y la historia eclesiástica, dándole a los archivos un carácter social y cultural y no sólo institucional, de alcance local y nacional (Rubio, 2007; Lemay, 2009; Oliveira, 2006; Gonzaga y Borges, 2009).

Algunos de los autores citados en este aspecto son: José Ramón Cruz Mundet (2003), Concepción Mendo Carmona (1995), Elio Lodolini (1993), María del Carmen Cayetano Martín (1989), Vicenta Cortés Alonso (1979), Fernando Borja de Aguinagalde (1988), Diego Navarro Bonilla (2003), Ildefonso Fernández Romero (2003), Mariano García Ruipérez (1999), Vivas (2005), etc. Estos han realizado valiosos aportes para este tipo de estudios en América Latina, sobre todo en lo que respecta al método para el tratamiento de las fuentes para la construcción histórica de la archivística y los archivos. Para tal análisis histórico:

[...] Las fuentes de carácter específicamente archivístico, aquéllas otras que inciden en la vertiente histórico-institucional, las regulaciones jurídicas y otras fuentes de carácter teórico son imprescindibles. Pero también lo son otras de carácter histórico, literario y simbólico de especial conveniencia para el estudio de la representación imaginaria de la disciplina (Vivas, 2005: 64).

Aunque algunos de los trabajos se enfocan a una construcción histórica de la disciplina durante el Antiguo Régimen, este modelo es completamente aplicable a estudios contemporáneos. Además se exponen un conjunto de hechos relacionados con la práctica documental y con la cultura escrita, en el cual se organiza y simplifica una red de relaciones que permiten establecer las fases y etapas en los orígenes de los archivos y de la archivística como disciplina, el cual señala Agustín Vivas (2004a) como el factor sociocultural de la archivística. 


\subsection{Memoria, derechos humanos y transparencia de la administración pública}

En los estudios sobre memoria se hacen abordajes discursivos que gravitan entre ensayos y estudios de caso, y que se enfocan en la recuperación de la memoria histórica y colectiva, su registro, conservación y transmisión (Restrepo, 2003; Vivas, 2004a; Ferrarezi y Sousa, 2007; Barros y Neves, 2009). Se habla de una creciente demanda social que se hace más evidente en el contexto latinoamericano, y como una forma de satisfacerla se ha empezado a dar una eclosión de los archivos respecto a las políticas de memoria y su relación con los derechos humanos. La existencia de archivos corrobora la necesidad humana de conservar determinado tipo de información para diversos fines, no sólo el de servir de testimonio a las administraciones (públicas o privadas), sino también el de constituirse en los depositarios de lo que se quiere recordar u olvidar. En esta relación entre archivo y memoria, uno de los autores más citados es el español Ramón Alberch Fugueras, cuyas reflexiones colocan a los archivos en una posición de centralidad política y de responsabilidad en cuanto a memoria y derechos humanos.

La función de recuperación de la memoria es una tarea educativa y cívica cargada de futuro en la que los archivos cuentan con el crédito de un ejercicio constante y comprometido en este objetivo a lo largo de la historia (Alberch, 2001:15).

Los archivos son tenidos en cuenta como parte esencial del patrimonio local, nacional y de la humanidad que sirve a los ciudadanos y los pueblos para la construcción de la memoria colectiva, el desarrollo de la identidad y el conocimiento de su cultura y tradiciones. Se expone la custodia de la memoria de los pueblos como la función social por excelencia de los archivos.

Tem-se, pois, que o arquivo é um sistema de informação social que se materializa em qualquer tipo de suporte, sendo caracterizado, principalmente, pela sua natureza orgânica e funcional associada à memória. Desse modo, a principal justificativa para a existencia do arquivo é a sua capacidade de oferecer a cada cidadão um senso de identidade, de história, de cultura e de memória pessoal e coletiva (Barros y Neves, 2009: 58).

Sin embargo, aunque los archivistas tienen plena conciencia de lo que representa la construcción social de la memoria, han reflexionado poco sobre ella en el ámbito latinoamericano, y menos desde un enfoque teórico. Se reconoce el valor de los archivos en la recuperación de la memoria histórica y 
en la construcción de la colectiva, pero algunos se limitan sólo a la disposición de los fondos documentales para su consulta, y pocos involucran al ciudadano del común. ${ }^{7}$

Aunque se entiende a los archivos como vitales para la recuperación social de la memoria, y por ende, para la construcción de las identidades (locales, regionales o nacionales) por medio de la garantía del derecho democrático de acceso a la información de los ciudadanos, es evidente que hace falta la valoración de estos como instituciones dinamizadoras de cultura, que en última instancia habrán de contribuir en la conservación de valores y al derecho del libre desarrollo de la personalidad, a través del intercambio de las costumbres y tradiciones plasmadas en el patrimonio documental.

En este sentido, los archivos adquieren no sólo una connotación de lugares de memoria, sino la de medios de conocimiento y representación, que posibilitan el reconocimiento de una realidad social, económica y política.

[...] portanto, faz com que o arquivo não se reduza à mera instituição de guarda da memória, mas extrapole tal função. Ele representa um forte meio necessário para a definição social e cultural, assumindo, assim, uma postura de mediação na conquista de direitos, no que tange à aquisição de informações e à criação de novos conhecimentos (Barros y Neves, 2009: 60).

Es en este sentido donde la difusión de los archivos es una de las tareas prioritarias como estrategia de intervención en el ámbito social (Campos, 2009). La visibilidad de la función social y cultural de los archivos debe ser una actividad que contribuya a la apropiación de la memoria y la construcción de ciudadanía, por lo que debe ser impulsada por medio de instrumentos legales y políticas públicas.

En este sentido los documentos y los archivos son elementos necesarios para los gobiernos y las administraciones públicas en sus actividades de gestión y administración del poder, como garantía de los derechos y reconocimiento de las obligaciones de los ciudadanos, ya que se consideran como medios de control y vigilancia incluso hacia la misma sociedad; de allí que se integren a la esfera pública como instituciones de extrema importancia en la democratización de la información. En depósitos legales de los documentos de los gobiernos, que a su vez son donde se encuentra registradas sus acciones, y que sirven de apoyo en todas las cuestiones del ámbito público, así como a la producción de sentido de ciudadanía.

7 Que son aquellas personas que no tienen contacto regular con los archivos, al contrario de investigadores y personas que laboran en instituciones públicas y privadas donde el archivo hace parte de la vida organizacional. 
Desse modo, os arquivos podem se estabelecer como esferas públicas informacionais, colocando-se como um fórum capaz de mediar o debate público. Isto significa entender o arquivo como um espaço que, embora não seja especificamente de comunicação, pode fazer desta uma atividade complementar, produzindo novos espaços de interação, potencializando a esfera pública, e proporcionando mais transparência às ações do Estado (Morigi y Veiga, 2007: 38).

De igual manera existe una latente inquietud expresada no sólo en los estudios en el ámbito de la memoria, sino también en los referidos a la administración de archivos, la gestión documental y TIC, ésta tiene que ver con la retención de la evidencia mediante procesos de conservación digital, y que se vuelve cada vez más importante a medida que muchos más fondos documentales son representados, caracterizados y descritos en línea, con el objetivo del mejoramiento de la accesibilidad a los servicios públicos, con especial énfasis en el derecho a la información, de lo que se deriva la connotación eadministración pública, la cual está estrechamente relacionada con la gestión documental en medios electrónicos (Casas, 2000; García, 2001; Ortego y Bonal, 2001; Roncaglio et al., 2004; Payer, 2005; Pacífico y Romão, 2006; Barreto, 2007, Sabés, 2008).

\subsection{La administración de archivos y la gestión documental en América Latina}

Los archivos entendidos desde su doble realidad, instituciones y documentos de archivo, es decir, continente y contenido, significa que debe aplicarse también una doble gestión. En este sentido, la administración de archivos y la gestión documental son abordadas como dos temas por separado, pero que se integran en la medida en que ambas se sirven una de la otra para sus propios fines. Antonia Heredia (2008: 45) dice que éstas:

[...] deberían distinguirse sin identificarlas, como más de un autor defiende, no faltando otros que han estimado dos modalidades de gestión referidas a los documentos según sean administrativos o históricos, mientras que no faltan quienes no hacen referencia expresa a la gestión o administración de Archivos quedándose sólo con la gestión documental, amén de quienes hablan de la una y de la otra sin distinguirlas.

La gestión documental o "gestión de documentos" es desarrollada como una corriente anglosajona de reciente aplicación pero ya generalizada, y la "administración de archivos", sus agentes, funciones y evolución, se asemeja 
con una tradición archivística encaminada al documento de conservación permanente, la cual ha sido de gran influencia para los países latinoamericanos en lo que respecta al área de los archivos, y en lo que atañe a las políticas archivísticas referidas al patrimonio documental.

Se insiste en la gestión documental o de documentos como eje transversal a cada una de las demás gestiones organizacionales (gestión de la información y del conocimiento), que debido a su aplicación y ampliación reciente no puede ser exclusivamente desarrollada por archivistas, de la misma manera en que deben ser estos quienes definan los criterios prioritarios (Heredia, 2008), y que además procura la mejor utilización y aprovechamiento de los recursos y servicios documentales, es decir, una economía de los documentos (Llansó, 1993), sobre todo en el contexto de los documentos archivísticos electrónicos o digitales, por lo que se habla de la gestión documental digital, y en esta medida:

[...] la gestión documental digital debe suponer una revisión y un ajuste de principios críticos, en especial porque ha rebasado una función testimonial autónoma para ampliar su alcance a la gestión de inteligencia en red, lo cual expande tanto su investigación, como su propio objeto de estudio (Hernández, 2007: 6).

En esta línea, los marcos teóricos que se desarrollan en los estudios referidos a la gestión documental y la administración de archivos se centran en la Teoría de la Archivística Integrada, como un punto de encuentro entre la archivística tradicional y la gestión documental, una zona de integración y consenso que debe en definitiva buscar el desarrollo mismo de la archivística como ciencia que estudia la conformación, conservación y técnicas para facilitar el uso de los fondos de archivo reales o virtuales, integrados por documentos de cualquier índole. En esta línea son trabajados Schellenberg, Duchein, Heredia, Cruz Mundet, Duranti, Cook, Llansó, entre otros (Roncaglio et al., 2004; Rodriguez, 2006; Indolfo, 2007; Heredia, 2008).

En esta temática se definen también relaciones conexas entre la gestión documental y la calidad total orientadas a la auditoria de la información, ésta entendida como la evaluación de la gestión de la información en la organización con el objetivo de identificar problemas y encontrar soluciones. En esta línea son referidos autores anglosajones como Ellis, D. (1993); Buchanan, S. (1998); Abell, A. y White, M. (1999).

En el campo de la gestión de documentos se puede definir la auditoría de información como un examen sistemático, planeado, organizado, que determina si las actividades y los resultados relacionados con la gestión de documentos cumplen con 
las disposiciones establecidas (métodos, procedimientos, etc.) y si éstas se aplican en forma efectiva para alcanzar los objetivos planteados, no sólo por la unidad responsable de la gestión documental sino por la organización (Gutiérrez, 2003: 17).

Aunque los trabajos más desarrollados en esta temática tratan sobre gestión documental y administración de archivos, los estudios de usuarios son presentados como determinantes para los archivos en tanto que contribuyen a planificar y diseñar sistemas y servicios acordes con las necesidades de los usuarios. Brindan la posibilidad de determinar las necesidades, demandas, y usos de información de los usuarios o clientes, y también permiten conocer en qué medida se satisfacen dichas necesidades.

Los estudios de usuarios son una poderosa herramienta en el trabajo diario de los archivos, independientemente de su fase, por cuanto aportan elementos científicos que permiten suministrar un servicio eficiente, eficaz y de calidad (Campos, 2009).

En la realización de los estudios de usuarios se combinan diferentes conocimientos que son el resultado de la aplicación de técnicas de investigación social, la teoría archivística y la estadística (Campos, 2009). Algunos autores citados en este tema son José Ramón Cruz Mundet, Alfonso Rubio Hernández y Luis Fernando Jaén García.

\subsection{El documento de archivo como fuente para la investigación y su valor probatorio}

Desde que se empezaron a generar documentos se han caracterizado por: su valor probatorio. Esta característica jurídica de los documentos aparece como una preocupación potencial en el área, pues no parece ser un asunto resuelto por el documento electrónico. Sabés (2008: 38), por ejemplo, señala que:

[...] con el documento electrónico es más complicado hablar de autenticidad por más que en los últimos años se haya impuesto la firma digital y la tecnología la ofrezca como solución a un gravísimo problema. Tampoco de integridad, ya que existe una desprotección, es decir, falta de control sobre la exactitud y actualización de los documentos de datos.

Este tema una vez abordado casi en su totalidad por la diplomática, y que significó una de las más importantes funciones de los archiveros en épocas pasadas, hoy parece tener poca atención. Tal valor probatorio pasa a ser un 
tema de preocupación para el records en medios electrónicos, el cual parece ser antagonista de la diplomática y sus técnicas documentales, dejando el tratamiento jurídico de los documentos de archivo sólo a los producidos en soporte de papel.

Aunque el documento de archivo no es abordado como fuente para la investigación como tal, existen estudios que lo conciben como indispensable para el análisis documental, visto este análisis como un proceso articulador entre el documento, su contenido y el esfuerzo intelectual para llegar a conocer sus elementos discursivos. Por ello Barité, Sagredo, Desantes, Núñez, Otlet y principalmente Fuster Ruiz abordan desde diferentes perspectivas el concepto de documento, y armonizan en afirmar que es un soporte material que sirve de amparo al conocimiento, por lo tanto se habla de análisis de documentos y análisis de información, igual que se habla de análisis documental e informacional. Estos autores consideran la información documental como la representación de un fenómeno, el cual condensa el conocimiento de algo o lo transforma. Sánchez y Vega (2003: 51) señalan que:

[...] las técnicas del análisis documental son una respuesta a las necesidades de la investigación y, por tanto, se erige como una técnica científica auxiliar de la investigación.

Los documentos archivísticos son expuestos como fundamentales, sobre todo, para la investigación histórica porque existe plena conciencia de su valor para la investigación en todas las áreas del saber, gracias a sus contenidos transdisciplinares y la variedad de sus soportes actuales.

\subsection{Tecnologias de la información y la comunicación. Aplicaciones en los archivos}

Los trabajos que abordan las tecnologías de la información en relación con los archivos enfatizan sobre los conceptos de sociedad de la información y del conocimiento, brecha digital, medios de comunicación, propiedad intelectual, protección de datos y multiculturalismo, entre otros. Para ello se remiten a teóricos de la sociedad de la información como Drucker, Dupuy, Castells y Martín-Barbero. Para ejemplificar, una de las definiciones más citada es:

Se crea un nuevo poder general: la Sociedad del Conocimiento y, como toda sociedad, tiene organizaciones con propósitos y funciones de integración del conocimiento como una tarea común, independiente de su visión de negocio (Drucker, 1996). 
La preocupación por el nuevo entorno social es evidente cuando los conceptos coinciden en que la labor de los profesionales de la información y la documentación deben asumir papeles más destacados en la creación, gestión y actualización de las nuevas tecnologías de la información y la comunicación con el objetivo de capitalizar la información circulante y en constante aumento.

Los grandes cambios producidos en la sociedad actual como consecuencia de la aparición de las TIC están transformando las funciones y el perfil de los profesionales de la información. Éstos se tienen que redefinir para adaptarse al nuevo mercado laboral, para lo cual deben actualizar sus contenidos (especialmente idiomáticos e informáticos) y agudizar determinadas habilidades interpersonales, como la creatividad, liderazgo, sentido de organización y capacidad de análisis, síntesis, comunicación y trabajo en equipo (Chaín y Más, 2009).

Para modernizar los archivos y hacerlos accesibles a públicos más amplios a través de sus sedes web, en el caso concreto de los archivistas, la modificación en los métodos de trabajo y en la forma de los documentos supone un impacto crucial sobre las tareas diarias de los archivos, tanto en la teoría y en la práctica archivística tradicionales como en la cultura documental. Así que difícilmente podrá darse una integración de los aspectos teóricos y metodológicos de la archivística con las TIC, sin una genuina apropiación de las distintas aplicaciones informáticas y soportes electrónicos, ópticos y magnéticos, que al igual que el papel, tienen sus propias características y cuidados especiales (Rodríguez, Montes de Oca y Dorta, 2002; Echeverría, 2008).

Todos los trabajos sobre esta temática coinciden en afirmar, implícitamente, que la solución al cambio puede venir de una modificación de mentalidad sobre los archivistas, así como del compromiso de las escuelas de formación archivística. Es decir, modificar la noción de un cambio a un desarrollo que no se centra en el tipo de documento sino en su utilización; no en el soporte sino en su contexto; no en su acceso sino en su intervención; no en su conservación sino en su producción. Por ejemplo:

La información de los mensajes de correo electrónico es usada ahora como prueba e insumo dentro de los procesos administrativos, gerenciales o jurídicos de cualquier organización. [...] Es un capital esencial no sólo por su valor, sino también por la utilidad que presta a sus usuarios, a la gestión, a la administración del organismo, a la ciencia, a la investigación y a la cultura de los pueblos y, claro, al seguimiento a los trámites efectuados en otro momento (Rodríguez y Rodríguez, 2005). 
Sin embargo, en la era digital, se pone en duda la integridad y autenticidad de los documentos electrónicos; es decir, la seguridad de la información y el valor probatorio, sobre todo en Internet, y es por eso que los trabajos en esta temática deben estar orientados al desarrollo de aplicaciones informáticas y software, hasta que se pueda definir una metodología para el tratamiento de estos documentos. Hernández (2007: 4), por ejemplo, expone que:

La unicidad, autenticidad y preservación documental, como principios de la nueva Archivística o Archivística Integrada, enfrentan los retos de la ubicuidad digital, de la manipulación dolosa y la obsolescencia tecnológica. El estudio profundo de los primeros fenómenos y la posibilidad de obtener herramientas para lidiar con los segundos son, a no dudarlo, aspectos esenciales para diseñar la «Web de la verdad» como un entorno confiable para la administración de la información.

\section{Conclusiones}

Las corrientes teóricas y conceptuales en archivística de la última década tienen que ver principalmente con los aspectos teóricos, la gestión documental y las tecnologías de la información y la comunicación. Al mismo tiempo se aborda con más carácter la discusión sobre la cientificidad de la archivística. La gestión documental es trabajada como proceso de la archivística integrada y los procesos de clasificación, valoración y conservación parecen ser los de mayor preocupación en el ámbito latinoamericano. En temas como la formación profesional de los archivistas se empiezan a integrar perfiles y modelos educativos que tienen en cuenta los componentes de investigación. En cuanto a los estudios de historia de los archivos y de la archivística se abordan nuevos enfoques: social, cultural e historiográfico.

Todo lo anterior podría significar que la comunidad de archivistas en América Latina está reclamando nuevos y mejores programas de formación específicos en archivística, independientes de su tradicional mezcla con la Bibliotecología, la Documentación y la Historia, que le hagan frente a los nuevos entornos de la sociedad de la información de cambios constantes y acelerados como la denominada e-administración pública. Lo que también explica que se hayan comenzado a buscar los orígenes y desarrollo particulares de la disciplina archivística y de su objeto de estudio: los archivos, debido a la inclusión de estos en nuevos ámbitos y áreas de la sociedad, por ejemplo, el mercado de la información, el ocio y el entretenimiento.

Por otro lado, y pese al papel destacado de los archivos en los procesos de calidad, control interno y gestión del conocimiento en las organizaciones 
en los últimos años, desde la archivística no han sido trabajados en términos investigativos, aun teniendo en cuenta que ésta es una nueva corriente que involucra desde las más altas instancias administrativas hasta la base organizacional, así como otros temas como la difusión de archivos y los estudios de usuarios, herramientas de vital importancia en la administración de archivos que apenas son tocados tangencialmente.

Tampoco es estudiado el documento de archivo como fuente para la investigación o elemento probatorio; mientras que el análisis documental y de contenido, como técnicas de investigación, son abordados desde un enfoque compartido con la bibliotecología y la documentación. De igual manera se plantea como necesaria la apropiación, por parte de la comunidad archivística, de lo requerido por las tecnologías de la información y la comunicación, una tarea prioritaria que debe pasar por una muy urgente reflexión, para la definición de metodologías de trabajo que contribuyan a mejores relaciones entre la sociedad y la información.

\section{REFERENCIAS BIBLIOGRÁFICAS}

Abell, A. y White, M. 1999. Developing content frameworks for intranets with information audits. The South Africa Journal of Information Management, vol. 1, no. 1.

Alberch Fugueras, Ramón et al. 2001. Archivos y cultura: manual de dinamización. Madrid: Ediciones Trea.

Álvarez Rodríguez, Mariela y Rodríguez, José David. 2005. El documento electrónico: ¿qué características debe cumplir de cara a las organizaciones del siglo XXI? Códice, vol. 1, no. 1, pp. 105-116.

Barreto, A.M. 2007. Memória e sociedade contemporânea: apontando tendências. Revista ACB, vol. 12, no. 2, pp. 161-176.

Barros, Dirlene Santos; Neves, Dulce Amélia de Brito. 2009. Arquivo e memória: uma relação indissociável. Transinformação, vol. 21, no. 1, pp. 55-61.

Bautier, Robert Henry. 1968. La phase cruciale de l'histoire des archives: la constitution des dépôts d'archives et la naisance de l'archivistique (XVIème - XIXème siècle). Archivum, XVIII.

Borja de Aguinagalde, Fernando. 1988. Elementos para una historia de los archivos y la archivística desde una perspectiva interdisciplinar. Irargi: Revista de Archivistica, no. 1, pp. 69-70.

Buchanan, S. 1998. The information audit: an integrated estrategic aproach. International Journal of Information Management, vol. 18 , no. 1 , pp. $29-47$

Campos Ramírez, Jafeth. 2009. La difusión en los archivos: importante herramienta de proyección ante la sociedad. Códice, vol. 5, no. 2, pp. 187-193. 
Campos Ramírez, Jafeth. 2009b. Los estudios de usuarios y los archivos: una alianza estratégica. Códice, vol. 5, no. 1, pp. 55-65

Casas De Barrán, Alicia. 2000. Gestión de documentos en países de Iberoamérica y el Caribe. Informatio, no. 5/6, pp. 89-113

Cayetano Martín, María del Carmen. 1989. Archivos municipales en América y España (S. XV-XVIII). Boletín de la ANABAD, vol. 1, no. XXXIX.

Chaín Navarro, Celia y Más Bleda, Amalia. 2009. Los archivos nacionales hispanoamericanos y la gestión de información de sus sedes web. Biblios, no. 35 .

Cortés Alonso, Vicenta. 1979. Archivos de España y América: Materiales para un manual. Madrid: Universidad Complutense.

Couture, Carol. 2001-2002. La formation et la recherche en archivistique: Éléments révélateurs de l'état de développement de l'archivistique contemporaine: Synthèse d'un projet de recherche. Archives, vol. 33, no. 2, pp. 21-51.

Cruz Mundet, José Ramón. 2003. Manual de archivística. 5a. ed. Madrid: Fundación Germán Sánchez Ruipérez.

Dorado Santana, Yanara y Mena Mugica, Mayra. 2009. Evolución de la ciencia archivística. Acimed, vol. 20, no. 1.

Drucker, Peter. 1996. La sociedad de los cambios. Bogotá: Editorial Norma, $316 \mathrm{p}$.

Echeverría, J. 2008. Apropiación social de las tecnologías de la información y la comunicación. Revista Iberoamericana de Ciencia, Tecnología y Sociedad, vol. 4, no. 10, pp. 171-182.

Ellis, D. et al. 1993. Information audits. Commucation audits and information mapping: a review summary. International Journal of Information Management, vol. 13, pp. 134-151.

Fernández Romero, Ildefonso. 2003. Tabularium: el archivo en época romana. Anales de documentación, no. 6.

Ferrarezi, Ludmila y Sousa Romão, Lucília Maria. 2007. Arquivo, documento e memória na concepção discursiva. Encontros Bibli, no. 24, pp. 152-171.

Fuster Ruiz, Francisco. 2001. Archivística, archivo, documento de archivo. Necesidad de clarificar conceptos. Biblios, vol. 2, no. 7.

García Pérez, Alexeis. 2001. La gestión de documentos electrónicos como respuesta a las nuevas condiciones del entorno de información. Acimed, vol. 9, no. 3, pp. 190-200

García Ruipérez, Mariano y Fernández Hidalgo, María del Carmen. 1999. Los Archivos Municipales en España durante el Antiguo Régimen: Regulación, conservación, organización y difusión. Cuenca: Universidad de Castilla-La Mancha.

Gilliland-Swetland, Anne y Mckemmish, S. 2006. Nuevos métodos investigación en archivística. España: Concejalía de Cultura de Cartagena.

Giraldo Lopera, Marta Lucía. 2009. Archivística: fundamentación teórica y tradición formativa. Revista Interamericana de Bibliotecología, vol. 32, no.1, pp. 31-45. 
Gonzaga Da Silva, Ana A. y Borges, Jussara. 2009. Arquivos secretos eclesiásticos em salvador. Informação E Informação, vol. 14, no. 2.

Gutiérrez Garzón, Liliana. 2003. La auditoria de información como herramientas de evaluación y mejoramiento de la gestión de documentos. Biblios, vol. 4, no. 16, pp. 14-22.

Heredia Herrera, Antonia. 2008. Gestión de documentos y archivos. Códice, vol. 4, no. 2, pp. 43-50

Indolfo, Ana Celeste. 2007. Gestão de documentos: uma renovação epistemológica no universo da arquivologia. Arquivística.net, vol. 3, no. 2, pp. 28-60.

Jaén García, Luis Fernando. 2006. La aplicabilidad de los estudios de usuarios en los archivos: el caso de los archivos históricos. Códice, vol. 2, no. 1, pp. 45-52.

2008. La formación archivística y la investigación. Códice, vol. 4, no. 2, pp. 51-61.

Lemay, Yvon. 2009. Art et archives: une perspective archivistique. Encontros Bibli, edición especial, pp. 64-86.

Lodolini, Elio. 1993. Archivística. Principios y problemas. Madrid: La Muralla, S. A., 357 p.

Llansó, Joaquim. 1993. Gestión de documentos: definición y análisis de modelos. Bergara: IRARGI, Centro de Patrimonio Documental de Euskadi.

Navarro Bonilla, Diego. 2003. La imagen del archivo: representación y funciones en España (siglos XVI y XVII). Gijón: Ediciones Trea.

Marín Agudelo, Sebastián Alejandro. 2010. Evolución, tendencias y perspectivas investigativas en archivos: consideraciones sobre la configuración científica de la archivística. Revista Interamericana de Bibliotecología, vol. 33, no. 2, pp. 337-359

2011. Estado de la producción científica en Archivística y archivos en América Latina 2000-2009. Una aproximación. Revista Interamericana de Bibliotecología, vol. 34, no. 3, pp. 257-269.

Mendo Carmona, C. 1995. El largo camino de la Archivística: de práctica a ciencia. Signo, Revista de Historia de la Cultura Escrita, no. 2, pp. 113-132

Morigi, Valdir Jose y Veiga, Alexandre. 2007. Esfera Pública Informacional: os arquivos na construção da cidadania. Informação E Sociedade: Estudos, vol. 17, no. 1, pp. 31-39.

Oliveira Santos, Cristian. 2006. Conhecer párrafo Conservar: Un Constituição e Dispersão dos Fundos Arquivísticos da Igreja Católica na Cidade de Goiás. Arquivistica.net, 2006, vol. 2, no. 2, pp. 52-69.

Ortego De Lorenzo-Cáceres, María del Pilar y Bonal Zazo, José Luis. 2001. Archivos en línea: formatos de difusión archivística en Internet. Biblios, vol. 2, no. 8.

Pacífico, Soraya Maria Romano; Romão, Lucília Maria Sousa. 2006. A memória e o arquivo produzindo sentidos sobre o feminino. Em questão, vol. 12, no. 1, pp. 73-90. 
Payer, Maria Onice. 2005. Discurso, memória e oralidade. Horizontes, vol. 23 , no. 1, pp. 47-56.

Restrepo Cuartas, Lucía. 2003. Voces y Memoria: El Archivo Sonoro de la Emisora Cultural Universidad de Antioquia: "La Voz de la Universidad”. Revista Interamericana de Bibliotecología, vol. 26, no. 1, pp. 37-5.1

Rivas Fernández, José Bernal. 2006. La sociedad del ocio: un reto para los archivos. Códice, vol. 2, no. 2, pp. 71-82

Rodriguez, Ana Márcia Lutterbach. 2006. A teoria dos arquivos e a gestão de documentos. Perspectivas em ciência da informação, vol. 11, no.1, pp. 102-117.

Rodríguez Mederos, Mabel, Montes De Oca Sánchez De Bustamante, Antonio, y Dorta Héctor, Juliemne. 2002. Utilización y conservación de los soportes electrónicos. Acimed, vol. 10, no. 6.

Romão, Lucília Maria Sousa. 2004. Na teia eletrônica, fragmentos da memória. En: Morello, Rosângela (Org.). Giros na Cidade: materialidade do espaço. Campinas: Editora da Unicamp, Labeurb.

Roncaglio, Cynthia, et al. 2004. Arquivos, gestão de documentos e informação. Encontros Bibli, edición especial, pp. 1-13.

Rubio Hernandez, Alfonso. 2003. Ciertas consideraciones sobre estudios de usuarios en archivos municipales. El archivo municipal de Logroño: una aproximación teórica y práctica. Revista Interamericana de Bibliotecología, vol. 26, no. 1, pp. 53-78.

2007. La escritura en el archivo. Mecanismo de dominio y control en el Nuevo Reino de Granada. Estudios políticos, no. 30, pp. 143-165.

Sabés Turmo, Fernando. 2008. Los documentos y archivos. Una necesaria revisión histórica para afrontar el reto de la e-administración pública. Enlace: Revista venezolana de información, tecnología y conocimiento, vol. 5, no. 2, pp. 31-45.

Sánchez Díaz, Marlery y Vega Valdés, Juan Carlos. 2003. Algunos aspectos teórico-conceptuales sobre el análisis documental y el análisis de información. Ciencias de la Información, vol. 34, no. 2, pp. 49-60

Sandri, Leopoldo. 1968. La stori degli archivi. Archivum, 1968, vol. XVIII.

Tanodi, Aurelio. 1961. Manual de Archivología hispanoamericana: teorías y principios. Córdoba: Universidad Nacional de Córdoba, 286 p.

Thomassen, Theo. 1997. Getting your drivers license on the electronic higway. Archivum, no. 43, pp. 330-340.

Vasquez Murillo, Manuel. 2006. Administración de documentos y archivos: Planteos para el siglo XXI. Buenos Aires: Alfagrama, 154 p.

Vivas Moreno, Agustín. 2004. El tiempo de la archivística: un estudio de sus espacios de racionalidad histórica. Ci. Inf., vol. 33, no. 3, pp. 76-96. 2004a. Factores socio-culturales para una historia de la archivística. Investigación Bibliotecológica, vol. 18, no. 36, pp. 117-137.

2005b. La representación de la historia de la archivística como método de investigación: las fuentes indirectas. Ciencias de la Información, vol. 36, no. 3. 
Ficha bibliográfica y analítica

\section{Información bibliográfica}

- Número de ficha:

- Título del artículo:

- Autor (es):

- Publicación:

- Lugar de edición:

- Medio de divulgación:

- Fecha:

- Idioma:

- Palabras clave:

- Resumen:

\section{Información analítica}

- Referencia bibliográfica:

- Problema central que se aborda y/o objetivos que propone:

- Hipótesis planteada:

- Marco teórico:

- Fuentes 0 autores en que sustenta su propuesta

a. Primarias:

b. Secundarias:

- Enfoques y herramientas metodológicas que propone:

- Conclusiones:

- Observaciones:

Diligenciada por:

Fecha de Diligenciamiento:

Anexo 2

Encuesta de investigación regional ${ }^{8}$

\begin{tabular}{|l|l|l|l|}
\hline \multicolumn{5}{|c|}{ Datos personales } \\
\hline Nombre: & \multicolumn{4}{|l|}{} \\
\hline Documento de Identidad: & \multicolumn{3}{|l|}{} \\
\hline Profesión: & \multicolumn{3}{|l|}{} \\
\hline Ciudad: & \multicolumn{3}{|l|}{} \\
\hline
\end{tabular}

Información institucional y general

Institución:

Dependencia:

Áreas\Líneas de investigación:

8 Esta encuesta fue traducida al portugués para el caso de la búsqueda de información en las escuelas de archivología y grupos de investigación de Brasil. 
¿Ha participado usted en investigaciones relacionadas con la archivística y los archivos?

¿Conoce usted grupos de investigación u otros investigadores en áreas relacionadas con la archivística y los archivos, que considere importante para esta investigación? ¿Cuales o quiénes?

Correo electrónico:

\section{Información sobre investigaciones en archivística y los archivos 2000-2009}

Nombre de la Investigación:

Objetivos de la investigación:

Resultados:

¿Es posible acceder a los

resultados? ¿Cómo?

\begin{tabular}{|l|l|}
\hline Fecha de inicio: & Fecha de finalización: \\
\hline
\end{tabular}

Anexo 3

Estrategias de búsquedas cuantificadas

\begin{tabular}{|c|c|c|}
\hline Estrategias de búsqueda & Resultados de búsqueda & Resultados válidos \\
\hline archivística & 39 & 4 \\
\hline archivología & 31 & 1 \\
\hline archivística and investigación & 9 & 1 \\
\hline archivística and historia & 17 & 2 \\
\hline archivística and administración & 12 & 1 \\
\hline archivística and control interno & 7 & 0 \\
\hline archivística and transparencia & 6 & 0 \\
\hline archivística and memoria & 13 & 1 \\
\hline archivística and administración pública & 12 & 2 \\
\hline archivística and derechos humanos & 9 & 1 \\
\hline archivística and tecnologías & 10 & 3 \\
\hline archivos and transparencia & 10 & 0 \\
\hline archivos and memoria & 9 & 1 \\
\hline archivos and historia & 11 & 1 \\
\hline archivos and investigación & 10 & 0 \\
\hline archivos and tecnologías & 12 & 3 \\
\hline archivos and control interno & 9 & 0 \\
\hline archivos and calidad & 9 & 1 \\
\hline archivos and derechos humanos & 11 & 1 \\
\hline archivos and administración & 12 & 2 \\
\hline archivos and administración pública & 10 & 1 \\
\hline Total & 268 & 26 \\
\hline
\end{tabular}


Anexo 4

Categorías de análisis y preguntas orientadoras para textos seleccionados

Categorías de análisis:

Archivística, archivos, investigación archivística, formación archivística, teoría archivística, historia archivística, transparencia, memoria, administración pública, democracia, derechos humanos, documentos de archivo, valor probatorio, fuentes de investigación, análisis documental, administración de archivos, gestión documental, control interno, calidad total, nuevas tecnologías, TICS, documentos electrónicos, digitalización de documentos.

Preguntas orientadoras:

- ¿Cuáles son los puntos de referencia teóricos?

- Expresiones utilizadas por los autores

- Establece el autor relaciones entre:

- Teoría e Historia Archivística

- Archivos, Memoria y Democracia

- Archivos e Investigación

- Archivos, Calidad y Administración

- Archivos y Nuevas Tecnologías

¿Es evidente la recolección sistemática de información para la construcción del texto?

¿Es posible deducir qué recepción tiene el texto en la comunidad archivística?

¿Qué otras relaciones establece el autor que no son objeto de interés en este estudio, y cuáles reciben mayor atención?

\section{Anexo 5}

Fuentes de información consultadas

\section{Bases de datos}

\begin{tabular}{|l|c|c|}
\hline \multicolumn{1}{|c|}{ Bases de datos } & Resultados & Resultados válidos \\
\hline Academic Search Premier & 44 & 7 \\
\hline Business Source Premier & 48 & 5 \\
\hline Fuente Académica & 56 & 8 \\
\hline Ulrichs Web & 34 & 0 \\
\hline $\begin{array}{l}\text { Library, Information Science } \\
\text { \& Technology Abstracts }\end{array}$ & 31 & 0 \\
\hline Happy Online & 22 & 0 \\
\hline Wilson Web & 33 & 6 \\
\hline \multicolumn{1}{|c|}{ Total } & 268 & 26 \\
\hline
\end{tabular}

\section{Revistas de Archivística, Bibliotecología, Ciencias de la Información y afines}

\begin{tabular}{|l|c|}
\hline \multicolumn{1}{|c|}{ Revistas } & Artículos \\
\hline $\begin{array}{l}\text { Acimed. } \\
\text { Cuba: Centro Nacional de Información de Ciencias Médicas. ISSN: 1530-2880 }\end{array}$ & 6 \\
\hline $\begin{array}{l}\text { Arquivistica.Net. } \\
\text { Brasil. ISSN: 1808-4826 }\end{array}$ & 32 \\
\hline
\end{tabular}




\begin{tabular}{|c|c|}
\hline $\begin{array}{l}\text { Biblios: Revista Electrónica de Bibliotecología, Archivología y Museología. } \\
\text { Perú: Universidad Peruana de Ciencias Aplicadas. ISSN: 1562-4730 }\end{array}$ & 16 \\
\hline $\begin{array}{l}\text { Ciência da Informacão. } \\
\text { Brasil: Instituto Brasileiro de Informação em Ciência e Tecnología /IBICT. } \\
\text { ISSN: 1518-8353 }\end{array}$ & 3 \\
\hline $\begin{array}{l}\text { Ciencias de la Información. } \\
\text { Cuba: Instituto de Información Científica y Tecnológica. ISSN: 0864-4659 }\end{array}$ & 10 \\
\hline $\begin{array}{l}\text { Códice. } \\
\text { Colombia: Universidad de la Salle/ Facultad de Sistemas de Información y } \\
\text { Documentación. ISSN: 1794-9815 }\end{array}$ & 27 \\
\hline $\begin{array}{l}\text { Encontros Bibli. } \\
\text { Brasil: Universidade Federal de Santa Catarina/ Centro de Estudios sobre la Universidad. } \\
\text { ISSN: 1518-2924 }\end{array}$ & 7 \\
\hline $\begin{array}{l}\text { Enlace: Revista Venezolana de Información, Tecnología y Conocimiento. } \\
\text { Venezuela: Universidad de Zulia. ISSN: 1690-7515 }\end{array}$ & 2 \\
\hline $\begin{array}{l}\text { Informação \& Informação. } \\
\text { Brasil: Universidade Estadual de Londrina/Centro de Educação, Comunicação e Artes/ } \\
\text { Departamento de Ciência da Informação. ISSN: 1981-8920 }\end{array}$ & 5 \\
\hline $\begin{array}{l}\text { Informação \& Sociedade: Estudos. } \\
\text { Brasil: Universidade Federal da Paraíba. 1809-4783 }\end{array}$ & 2 \\
\hline $\begin{array}{l}\text { Información, Cultura Y Sociedad. } \\
\text { Argentina: Universidad de Buenos Aires/Instituto de Investigaciones Bibliotecológicas. } \\
\text { ISSN: 1851-1740 }\end{array}$ & 4 \\
\hline $\begin{array}{l}\text { Informatio: } \\
\text { Uruguay: Universidad de La República/Escuela Universitaria de Bibliotecología y Ciencias } \\
\text { Afines. ISSN: 0797-1435 }\end{array}$ & 4 \\
\hline $\begin{array}{l}\text { Investigación Bibliotecológica: } \\
\text { México: Universidad Nacional Autónoma de México/ Centro Universitario de } \\
\text { Investigaciones Bibliotecológicas. ISSN: 0187-358X }\end{array}$ & 5 \\
\hline $\begin{array}{l}\text { Perspectivas em Ciência da Informação. } \\
\text { Brasil: Universidade Federal de Minas Gerais/ Escola de Ciência da Informação. ISSN: } \\
\text { 1981-5344 }\end{array}$ & 5 \\
\hline $\begin{array}{l}\text { Pontodeacesso. } \\
\text { Brasil: Universidade Federal da Bahia/ Instituto de Ciência da informação. } \\
\text { ISSN: 1981-6766 }\end{array}$ & 15 \\
\hline $\begin{array}{l}\text { Revista Acb. } \\
\text { Brasil: Universidade Federal de Santa Catarina UFSC/Departamento de Ciência da } \\
\text { Informação. ISSN 1414-0594 }\end{array}$ & 4 \\
\hline $\begin{array}{l}\text { Revista Interamericana de Bibliotecología. } \\
\text { Colombia: Universidad de Antioquia/Escuela Interamericana de Bibliotecología. ISSN: } \\
\text { 0120-0976 }\end{array}$ & 4 \\
\hline $\begin{array}{l}\text { Transinformação. } \\
\text { Brasil: PUC-Campinas. ISSN: 0103-3786 }\end{array}$ & 2 \\
\hline Otras revistas & 5 \\
\hline Total & 158 \\
\hline
\end{tabular}

